\title{
Comparison between intravenous and intragastric alcohol self-administration
}

\author{
STANLEY G. SMITH, TOREEN E. WERNER, and W. MARVIN DAVIS \\ Department of Pharmacology, University of Mississippi, University, Mississippi 38677
}

\begin{abstract}
Rats were allowed to self-administer solutions of either saline or alcohol (in unit doses of .03, .1, .3, 1.0, and $3.0 \mathrm{mg} / \mathrm{kg} /$ infusion) by both intravenous and intragastric routes. Data from intravenous subjects showed a trend for the number of infusions to decrease and for the amount of drug self-administered to increase with increases in the unit dose made available. Data from the intragastric subjects showed a trend for both number of infusions and amount of drug self-administered to increase with increases in unit dose. Comparison between routes indicated that more infusions were taken, and a greater amount of drug was self-administered with the intravenous route at doses of $.1, .3$, and $1.0 \mathrm{mg} / \mathrm{kg} /$ infusion. However, more intragastric infusions were taken at $3.0 \mathrm{mg} / \mathrm{kg} /$ infusion.
\end{abstract}

Ethyl alcohol (EA) has been demonstrated to be self-administered both by the intravenous route (Deneau, Yanagita, \& Seevers, 1969; Woods, Ikomi, \& Winger, 1971; Smith \& Davis, 1974; Smith, Werner, \& Davis, Note 1) and by the intragastric route (Marfaing-Jallat. Pruvost, \& Le Magnen, 1974; Smith, Werner, \& Davis, Note 2; Yanagita \& Takahashi. Note 3). The doses of EA self-injected by the intravenous or intragastric routes ranged from $.12 \mathrm{mg} / \mathrm{kg} /$ infusion to $200 \mathrm{mg} / \mathrm{kg} /$ infusion. While a wide range of doses has been found effective in maintaining self-administration behavior, the attention in the above-cited studies was on variables other than dose; few employed more than a single dose. Thus, directly comparable dose-effect data, within or between routes, are not available. The present research was an attempt to provide such data for the intravenous and the intragastric routes in the rat.

\section{METHOD}

\section{Subjects}

The subjects were adult male rats of Sprague-Dawley descent. Thirty rats were used for Experiment I and 30 for Experiment II. All were drug naive at the start of the experiment. Water and food were available ad lib in both the home cage and experimental chamber throughout the experiment.

\footnotetext{
Apparatus

Rats for Experiment I were implanted with a chronic indwelling jugular catheter which passed from the jugular vein subcutaneously to an exit on the upper back (for details, see Smith \& Davis, 1975). Rats for Experiment II were surgically prepared with a chronic esophageal intragastric cannula, which passed from the esophagus subcutaneously to an exit on the upper back (for details, see Smith, Werner, \& Davis, 1975). At the back, each type of catheter was attached to an external harness and the harness to a length of needle tubing which in turn led to a leakproof swivel at the top

This research was supported by PHS Grant AA01217-01 and in part by the Research Institute of Pharmaceutical Sciences School of Pharmacy, University of Mississippi. Reprints may be obtained from any author at the Department of Pharmacology. University of Mississippi, University, Mississippi 38677.
}

center of the chamber. The opposite end of the swivel was connected by vinyl tubing to an infusion pump which delivered $.023 \mathrm{ml}$ (Experiment I) or $.092 \mathrm{ml}$ (Experiment II) of .9\% saline solution or EA solution in $.25 \mathrm{sec}$ (Experiment I) or $1 \mathrm{sec}$ (Experiment II) each time it was activated. The experimental chambers, clear plastic cylinders of $24 \mathrm{~cm}$ height and $25 \mathrm{~cm}$ diam, contained a response lever, food, and water. Each chamber was lighted and enclosed within a ventilated sound-attenuated compartment. Leverpresses were registered on electromechanical counters, and all programming was accomplished via solid state electronic circuitry.

\section{Procedure}

The subjects were placed in the test chambers, attached to the injection system, and allowed a 1-h period for adaptation to the chambers. Following adaptation, the operant level of leverpressing was determined for a 10 -h period during which each response was followed by an intravenous (Experiment I) or an intragastric (Experiment II) infusion of saline. Superimposed on the infusion interval was a buzzer presentation of equal duration. On each of the subsequent 5 days, a $10-\mathrm{h}$ period of access to either intravenous or intragastric infusions of EA was allowed. The unit doses employed for each route were 0 (saline), .03, .1, .3, 1.0, and $3.0 \mathrm{mg} / \mathrm{kg}$ /infusion. Each experiment employed five different rats at each unit dose, for a total of 30 subjects. Statements concerning statistical comparison between treatments refer to data on Day 5 and are derived from Student's t test using two-tailed probability distribution.

\section{RESULTS}

Figure 1 shows the number of intravenous infusions taken by subjects at each dose level in Experiment I. The data indicate a trend for reduction in numbers of infusions as the unit dose was increased. Saline and EA, $.03 \mathrm{mg} / \mathrm{kg} /$ infusion, did not maintain selfadministration and did not differ significantly $(p>.05)$ on Day 5. The lower two doses which did maintain self-administration, .1 and $.3 \mathrm{mg} / \mathrm{kg}$, and the two higher doses, 3.0 and $1.0 \mathrm{mg} / \mathrm{kg} /$ infusion, each constituted pairs which were not significantly different $(p>.05)$. Otherwise, all doses were significantly different from each other and from saline $(\mathrm{p}<.01)$. 


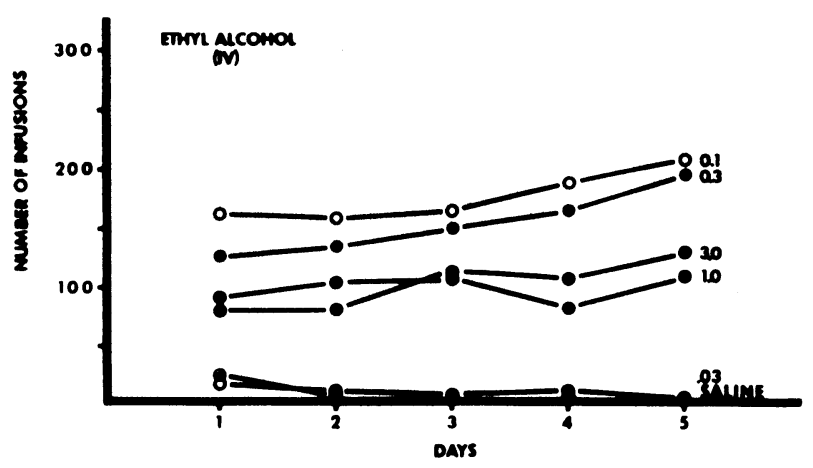

Figure 1. Mean number of infusions of intravenous alcohol taken at different unit doses.

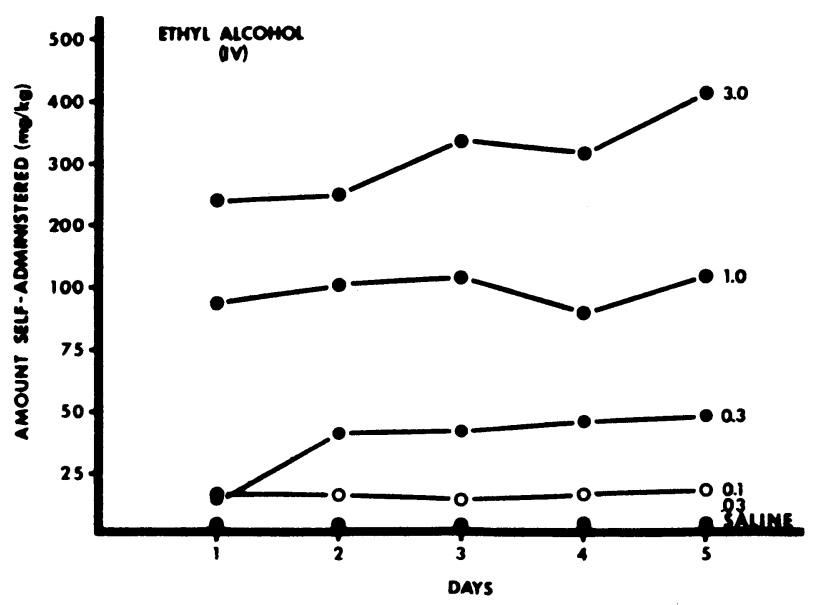

Figure 2. Mean amount of intravenous alcohol (mg/lge) self-administered at different unit doses.

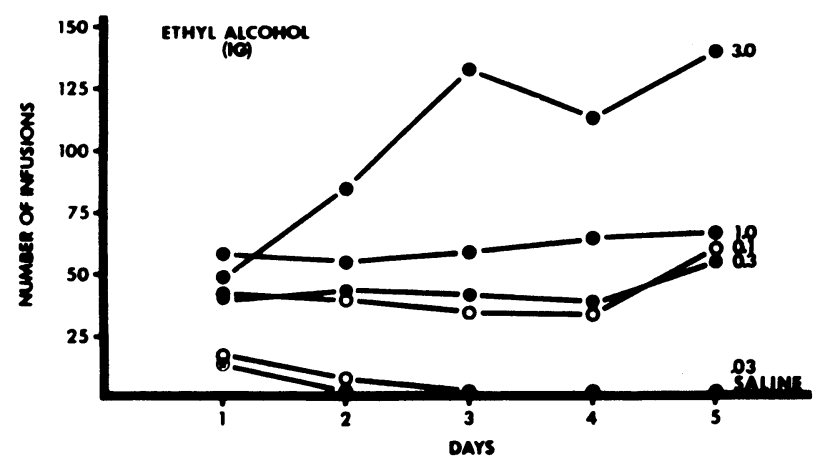

Figure 3. Mean number of infusions of intragastric alcohol taken at different unit doses.

Figure 2 shows the amount of drug $(\mathrm{mg} / \mathrm{kg})$ self-administered intravenously by subjects receiving different unit doses. The data indicate that the amount of EA taken was directly related to the unit dose, i.e., the larger the unit dose the more drug self-administered. With the exception that saline and the $.03 \mathrm{mg} / \mathrm{kg} /$ dose did not differ $(\mathrm{p}>.05$ ), all other doses differed significantly from saline and one another $(\mathrm{p}<.01)$.
Figure 3 shows the number of intragastric infusions taken in Experiment II. These data indicate a general trend for taking increased numbers of infusions with increases in unit dose. Saline and the .03 $\mathrm{mg} / \mathrm{kg} /$ group were not significantly different $(p>.05)$ and did not maintain self-administration behavior. Data for .3, .1, and $1.0 \mathrm{mg} / \mathrm{kg} /$ groups also did not differ, but they did maintain drug-taking behavior and each was significantly different from saline, .03 and $3.0 \mathrm{mg} / \mathrm{kg} /$ doses $(\mathrm{p}<.01)$.

Figure 4 shows that the amount of drug taken by the intragastric route increased as the unit dose was increased. Statistical analysis indicates that the saline, .03 and $.1 \mathrm{mg} / \mathrm{kg} / \mathrm{groups}$ did not differ. Doses of $.3,1.0$, and $3.0 \mathrm{mg} / \mathrm{kg}$ /infusion differed from one another and from the lower doses and saline $(p<.01)$.

Comparisons between the intravenous and intragastric routes for number of infusions indicated that more intragastric than intravenous infusions were taken at $3.0 \mathrm{mg} / \mathrm{kg} /$ infusion $(\mathrm{p}<.01)$, while more infusions were taken by intravenous subjects at $.1, .3$, and $1.0 \mathrm{mg} / \mathrm{kg}$ /infusion $(\mathrm{p}<.01)$. No differences were observed between routes for saline and $.03 \mathrm{mg} / \mathrm{kg} /$ infusion $(\mathrm{p}>.05)$. For the amount of alcohol self-administered $(\mathrm{mg} / \mathrm{kg} / \mathrm{session})$, saline and the dose of $.03 \mathrm{mg} / \mathrm{kg}$ /infusion did not differ ( $p>.05$ ). As with number of infusions, the amount of EA self-administered was significantly greater for the intragastric route at $3.0 \mathrm{mg} / \mathrm{kg}$ and for the intravenous route at $.1, .3$, and $1.0 \mathrm{mg} / \mathrm{kg} /$ infusion $(\mathrm{p}<.01)$.

\section{DISCUSSION}

The general trend for number of infusions by the intravenous subjects was for a decreased number of infusions with increases in the unit dose. An opposite trend was observed for the amount (dosage) self-administered. Number of infusions should be expected to first increase and then decrease with increasing unit dose for intravenous rats, for with the increased unit dose greater effects of satiation and

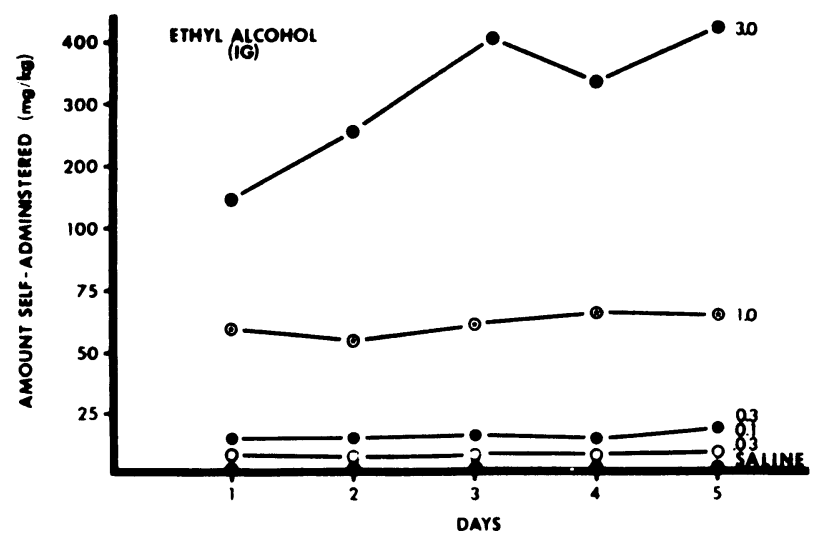

Figure 4. Mean amount of intragastric alcohol $(\mathrm{mg} / \mathbf{k g})$ self-administered at different unit doses. 
sedation on behavior should result. Also, larger amounts of EA should be self-administered $(\mathrm{mg} / \mathrm{kg})$ as the unit dose increases, for subjects at lower unit doses would need to respond 10 to 30 times in order to equal a single response at the higher doses. On the contrary, the general trend for the intragastric subjects was for increases both in number of infusions and in amount self-administered with increases in unit dose. Evidently, the suppression of responding attributed to sedation and satiation does not occur within this dose range because of the much-delayed absorption and distribution by the intragastric route in contrast to the intravenous route.

The patterns described above for intravenous EA are similar to those observed for intravenous morphine (Weeks \& Collins, 1971; Smith, Werner, \& Davis, Note 4). The patterns described for intragastric EA are similar to those recorded for intragastric medazepam (Gostestam, 1973).

If one compares the range of intravenous doses at which EA has been found effective, .12 to $200 \mathrm{mg} / \mathrm{kg} /$ infusion, to that for morphine sulfate, .03 to $10 \mathrm{mg} / \mathrm{kg}$ /infusion, EA appears less potent. Also, if one considers the doses commonly employed in discriminative conditioning research, EA at $1,000-3,000 \mathrm{mg} / \mathrm{kg}$, and morphine at $9-36 \mathrm{mg} / \mathrm{kg}$ intraperitoneally, it is quite apparent that EA is much less potent (Overton, 1971). However, EA is more readily absorbed from the stomach than morphine (Wallgren \& Barry, 1971; Reynolds \& Randall, 1957). Thus, intragastric EA should be absorbed so as to produce reinforcing effects significantly sooner than intragastric morphine. Therefore, larger differences should be expected between the two routes for morphine than for alcohol, especially at low and medium doses.

Taking into account the reduced reinforcing effectiveness, discriminative qualities, and satiating and sedating effects of EA, it is not surprising that intravenous EA did surpass intragastric at some dosages. These data would suggest that larger differences between EA unit doses may be required to observe such differences between routes as have been demonstrated for morphine.

\section{REFERENCE NOTE}

1. Smith, S. G., Werner, T. E., \& Davis, W. M. The intravenous self-administration of alcohol in the rat. Paper presented at
Southeastern Psychological Association meeting, Hollywood, Florida, May 1974.

2. Smith, S. G., Werner, T. E., \& Davis, W. M. Intragastric self-administration of abuse drugs by rats. Paper presented at Southeastern Psychological Association meeting, Hollywood, Florida, May 1974.

3. Yanagita, T., \& Takahashi, S. Dependence liability of several hypnotic-antianxiety agents evaluated in monkeys. Paper reported to the Committee on Problems of Drug Dependence, Palo Alto, California, February 1971.

4. Smith, S. G., Werner, T. E., \& Davis, W. M. Analysis of dose effect and tolerance for intragastric and intravenous morphine self-administration. Paper presented at Southeastern Psychological Association meeting, Atlanta, Georgia, March 1975.

\section{REFERENCES}

Deneau, G., Yanagita, T., \& Seevers, M. H. Selfadministration of psychoactive substances by the monkey. Psychopharmacologia, 1969, 16, 30-48.

GotestaM, K. G. Intragastric self-administration of medazepam in rats. Psychopharmacologia, 1973, 28, 87-94.

Marfaing-Jallat, P., Pruvost, M., \& Le Magnen, J. La consommation de ethanol par auto-administration intragastrique chez le rat. Journal de Physiologie (Paris), 1974, 68, 81-95.

Overton, D. A. Discriminative control of behavior by drug states. In T. Thompson \& R. Pickens (Eds.), Stimulus properties of drugs. New York: Appleton-Century-Crofts, 1971.

Reynolds, A. K., \& Randall, L. I. Morphine and allied drugs. Toronto: University of Toronto Press, 1957.

SMITH, S. G., \& DAvis, W. M. Intravenous alcohol self-administration in the rat. Pharmacological Research Communications, 1974, 6, 397-401.

Smith, S. G., \& Davis, W. M. A method for chronic intravenous drug administration in the rat. In S. Ehrenpreis \& A. Neidle (Eds.), Methods in narcotic research. New York: Dekker, 1975.

Smith, S. G., Werner, T. E., \& Davis, W. M. Technique for intragastric delivery of solutions: Application for selfadministration of morphine and alcohol by rats. Physiological Psychology, 1975, 3, 220-224.

Wallgren, H., \& BARRY, H. Actions of alcohol: Biochemical, physiological and psychological aspects. New York: American Elsevier Publishing Company, Inc., 1971.

WeEks, J. R., \& Collins, R. J. Primary addiction to morphine in rats. Federation proceedings, 1971, 30, 1967.

Woods, J. H., IкомI, F., \& Winger, G. D. The reinforcing property of ethanol. In M. K. Roach, W. M. McIssac, \& P. J. Creaven (Eds.), Biological aspects of alcohol. Austin: University of Texas Press, 1971.
(Received for publication July 4, 1975; August 28, 1975.) 